Avaliado pelo sistema double blind review

Recebido: 07 dez 2017 | Revisado: 08 mai 2018 | Aprovado: 21 ago 2018

\title{
Perfil dos produtores brasileiros e paraguaios que obtiveram altas produtividades na safra de soja 2016/2017
}

Profile of brazilian and paraguayan producers who got high productivity in soy safra 2016/2017

\author{
Andreison Christian Saran Aneli ${ }^{(1 D}$, Mauricio Messias Quarezemin ${ }^{2}$ (iD), Helton Aparecido Rosa ${ }^{3}$ (iD e \\ Jonathan Dias Ferreira ${ }^{4}$ \\ ${ }^{1}$ Centro Universitário FAG, especialista em Gestão de Agronegócio, programa de Pós-Graduação do Centro Universitário FAG, \\ email: andreison.aneli@outlook.com \\ ${ }^{2}$ Centro Universitário FAG, especialista em Gestão de Agronegócio, programa de Pós-Graduação do Centro Universitário FAG, \\ e-mail: mauriciomessias949@gmail.com \\ ${ }^{3}$ Centro Universitário FAG, doutor em Engenharia Agrícola, e-mail: helton.rosa@ hotmail.com \\ ${ }^{4}$ Centro Universitário FAG, doutorando em Administração, programa de Pós-Graduação da Universidade Estadual de Maringá \\ (UEM), e-mail: jonathanferreiraa@hotmail.com
}

\section{RESUMO}

A Safra brasileira de soja 2016/2017 consolidou-se com recordes de produção e produtividade, assim como no Paraguai que obteve uma excelente safra. Esse fato foi obtido graças a um alto emprego de tecnologia pelos produtores e boas condições climáticas durante a safra. Aproveitando o fato da ocorrência de uma excelente safra de soja, foi realizado um estudo com produtores que se destacaram dos demais com a obtenção de altas produtividades. Com esse estudo objetivou-se analisar o perfil desses produtores numa determinada região do Brasil e do Paraguai, fazendo um comparativo entre os dois casos. Foram encontradas semelhanças entre os produtores quanto ao uso de tecnologia. Em relação ao perfil dos produtores foi observado que os produtores brasileiros são mais dependentes de assistência técnica e dos canais de venda, que são o canal para se manterem atualizados sobre o meio rural. Os produtores são mais independentes das empresas vendedoras de insumos no Paraguai, e utilizam os meios de comunicação para se atualizarem.

Palavras-chave: Tecnologia. Produção. Agricultores.

\begin{abstract}
The 2016/2017 Brazilian soybean crop consolidated with records of production and productivity, as well as in Paraguay, which obtained an excellent harvest. This fact was obtained thanks to a high use of technology by the producers and good climatic conditions during the harvest. Taking advantage of the fact of the occurrence of an excellent soybean crop, a study was carried out with producers who stood out from the others with the obtaining of high productivities. The purpose of this study was to analyze the profile of these producers in a particular region of Brazil and Paraguay, comparing the two cases. Similarities were found among producers regarding the use of technology. Regarding the profile of producers, it was observed that Brazilian producers are more dependent on technical assistance and sales channels, which are the channel to keep up-to-date on the rural environment. The producers are more independent of the companies that sell inputs in Paraguay, and use the means of communication to update themselves.
\end{abstract}

Keywords: Technology. Production. Farmers.

Ciências Sociais Aplicadas em Revista, v. 20, n. 38, p. 167-185, semestral, janeiro-junho, 2020. 


\section{INTRODUÇÃO}

A cultura da soja é produzida em diversos países do mundo e tem grande importância econômica. O Brasil é o segundo produtor mundial de soja, ficando atrás apenas dos EUA. Na safra 2015/2016 a cultura ocupou uma área de 33,17 milhões de hectares, totalizando uma produção de 95,63 milhões de toneladas, com uma produtividade média de $2.882 \mathrm{~kg}$ por hectare (EMBRAPA SOJA, 2017).

O Estado do Paraná lidera a produtividade na soja e no milho na safra de 2016, segundo os dados do levantamento sistemático de produção agrícola divulgado pelo IBGE. O rendimento por hectare na soja deve chegar a 3.405 quilos por hectare (IPARDES, 2017).

Na safra brasileira de soja 2016/2017, consolida-se o crescimento da área plantada de 1,9\% em relação ao plantio da safra anterior. Esse aumento, aliado ao uso do melhor pacote tecnológico disponível, ajudado pelas boas condições climáticas durante o ciclo da cultura, foram os responsáveis pela safra recorde. O aumento de produtividade da oleaginosa também se deve a mudança no perfil tecnológico dos produtores, com a consolidação de materiais transgênicos de alto rendimento (CONAB, 2017).

Além do meio ambiente, a expressão do potencial produtivo da soja depende de técnicas adequadas de cultivo (preparo do solo, controle de pragas, doenças e plantas daninhas, sistema de plantio, cultivares), de fatores físicos do solo (matéria orgânica, umidade, temperatura, textura), e fatores químicos relacionados a fertilidade do solo (CAMPO e HUNGRIA, 2000).

Em um estudo no Paraguai realizado por Marcos Glauser, apontou que cerca de 2/3 das terras nacionais pertencem a brasileiros (GLAUSER, 2009). Além disso, em uma amostra de 28 empresas do agronegócio paraguaio realizado por Luis Rojas, apresentou que $50 \%$ das principais empresas envolvidas com o setor no país, possuem características dos chamados brasiguaios (ROJAS, 2009).

Esses produtores brasileiros começaram a cruzar a fronteira em busca de terras férteis nos anos de 70 e 80. Dos estimados 700.000 entre gaúchos, catarinenses e paranaenses que foram para o Paraguai, apenas metade permanece nos pais até hoje. Os brasileiros introduziram não só a soja, mas também as técnicas modernas de plantio, mecanização e transgênicos na agricultura. Atualmente o Paraguai busca aproveitar o bom momento para impulsionar a indústria e diversificar a economia (BOSCO, 2014).

Ciências Sociais Aplicadas em Revista, v. 20, n. 38, p. 167-185, semestral, janeiro-junho, 2020. 
A dinâmica do setor agrícola e muito complexa e traz consigo diversas analises sobre o que influencia a estrutura produtiva no campo, que vai muito além do manejo realizado pelo agricultor. Como relata Vieira Filho e Silveira (2012), que algumas lições devem ser entendidas, destaque para o papel dos investimentos no processo produtivo, que gera novos produtos e inovações, a combinação mais eficiente dos insumos tecnológicos, que garante vantagens comparativas, e ainda a capacidade de absorção destes conhecimentos pelos produtores.

Nesse contexto o objetivo deste trabalho foi analisar o perfil dos produtores que obtiveram altas produtividades, fazendo um comparativo entre os perfis dos produtores do Brasil e do Paraguai.

\section{PRODUÇÃO DE SOJA BRASILEIRA E PARAGUAIA}

Fato importante para se entender a produtividade está na orientação técnica, de acordo com Felema, Raiher e Pereira (2013) mais de 20\% receberam esse tipo de orientação, estando os Estados da região Norte e Nordeste, $60 \%$ dos estabelecimentos avaliados não dispuseram de qualquer tipo de assistência técnica. O mesmo autor afirma que a concentração de culturas de elevada produtividade em algumas regiões do país, está concomitantemente relacionada com a concentração tecnológica na região. Segundo o mesmo autor, em seu trabalho buscou identificar os fatores determinantes na produtividade do trabalho e da terra na agropecuária brasileira. Os insumos agrícolas e a mecanização foram os fatores que tiveram participação positiva na maior parte dos estados avaliados.

Para Moreira (1991), a produtividade é entendida com uma relação entre o que foi produzido, dado o sistema de produção, e os insumos utilizados num certo período de tempo, e a disponibilidade da área, aliada a tecnologia em pregada no processo produtivo, senso assim o fator terra e o trabalho configuram-se essenciais para o aumento da produtividade.

O uso intensivo de sementes selecionadas, de fertilizantes e outros agroquímicos, como forma de impulsionar maiores produtividades da terra, aliado a presença das máquinas agrícolas no processo produtivo, incrementa a produtividade do trabalho (GONÇALVES e NEVES, 2007).

Gray, Jackson e Zhao (2011), estabelecem que as melhorias e os novos conhecimentos que visem modificar as práticas produtivas conduzem as maiores produtividades. A mudanças tecnológicas ligadas a máquinas, melhoramentos de defensivos agrícolas e novas cultivares foram e são decisivas para melhor eficiência na produção agrícola. Os investimentos em pesquisa e 
desenvolvimento são outra parte importante para alcance de maior produtividade, pois é a origem dos avanços tecnológicos.

Conforme Vieira Filho e Silveira (2011), a eficiência produtiva também está relacionada a capacidade de absorção e difusão das novas tecnologias em todo o meio agrícola. Dado um conjunto institucional promotor do desenvolvimento, os ganhos nas produtividades estarão ligados a capacidade de absorção e aprendizado das classes inovadoras, ou seja, difusão do conhecimento pelas instituições agrícolas. Segundo os mesmos autores, produtores inovadores são mais receptivos as novas tecnologias e, assim, conseguem maximizar ganhos produtivos e reduzir custos.

Segundo EMBRAPA SOJA (2017), e tomando como exemplo os relatos dos vencedores dos concursos de máxima produtividade de soja no Brasil, promovido pelo CESB (Comitê estratégico soja Brasil), pode-se citar sete pontos em destaque comum a esses produtores vencedores: Adoção do sistema de plantio direto; Correção do perfil do solo; Ajuste da adubação para o potencial produtivo esperado; Utilização de cultivares altamente produtivas, adaptadas e com estabilidade de produção; Arranjo espacial de plantas; Controle de plantas daninhas, pragas e doenças; Zelo do produtor na condução da lavoura, desde a semeadura até a colheita.

Para a obter altas produtividades, o segredo está no somatório de detalhes que necessariamente passam pela correção do solo e pelo fornecimento dos nutrientes as plantas, uso de práticas que possibilitam as plantas expressar todo o seu potencial genético. Quando conseguirse anular ou minimizar os fatores que limitam a produtividade, e promover as interações que propiciem ganho de rendimento, pondera-se alcançar o máximo de produtividade.

No concurso de produtividade realizado pelo CESB, publicado pelo Projeto Soja Brasil (CANAL RURAL, 2015), o campeão em produtividade foi o produtor Alisson Hilgemberg de Ponta Grossa/PR, que colheu 140 sacas por hectare. O produtor conseguiu praticamente triplicar sua produtividade em comparação com a média nacional. A colheita campeã foi obtida em cinco hectares dos 590 que cultiva. A média total de sua área foi de 93 sacas/ha. O produtor relata que o segredo é o plantio direto, pois há mais de 30 anos que vem estruturando o solo e sempre repondo a matéria orgânica. A partir de 2008 passou a adotar a agricultura de precisão. Então essa resposta de altas produtividades se deve um solo bem estruturado, fornecendo os nutrientes necessários. Outra prática adotada é a cobertura do solo. O produtor utiliza aveia preta há 11 anos seguidos sem nunca ser colhida. A palhada é toda utilizada no plantio direto da soja. O custo total de produção é de R 1.800 por hectare explica Hilgemberg. 
A premiação de máxima produtividade do CESB incentiva os produtores de todo o Brasil a trabalharem melhor o manejo e uso de tecnologia para atingir altas produtividades. Não é apenas um fator isolado que garante alta produtividade. Todos os fatores precisam ser trabalhados em conjunto: histórico de perfil de solo, manejo, maquinário, período de aplicação, etc. São uma série de itens que farão a soja exercer todo o seu potencial afirma o presidente do CESB, Nery Ribas (CANAL RURAL, 2015).

A safra brasileira de soja 2016/2017 foi consolidada como um recorde, apresentando crescimento da área plantada de 1,9\%, comparado com o ano anterior, e produção de 113,9 milhões de toneladas. O excelente desempenho da cultura foi obtido graças ao bom comportamento do clima em praticamente todas as regiões do pais. Na região Sul, no geral foram boas as produtividades alcançadas devido a regularidade das precipitações, boa insolação e manejo adequado das lavouras (CONAB, 2017).

No Estado do Paraná a área plantada com a oleaginosa totalizou 5.249,6 mil hectares, apresentando rendimentos médios de $3.721 \mathrm{~kg} / \mathrm{ha}$. As boas condições climáticas durante a safra, e a adoção de tecnologia são as responsáveis por esta excelente produtividade, com safra recorde e produção total $16 \%$ acima da safra passada (CONAB, 2017).

O Paraná também é o primeiro do mundo na produtividade de soja. Com a produção de 3,6 toneladas por hectare, supera a média colhida nos Estados Unidos maior produtor do planeta em 4\%, que atingiu 3,5 ton/ha. Segundo o Secretário da Agricultura e Abastecimento do Estado do Paraná, Norberto Ortigara, estes números confirmam a eficiência dos produtores rurais paranaenses, que ano a ano, buscam aprimorar o desenvolvimento tecnológico como forma de melhorar a produtividade e a rentabilidade das lavouras. $O$ Instituto Paranaense de Desenvolvimento Econômico e Social (Ipardes) estima que o PIB do agronegócio paranaense suba 1,5\% nesse ano, contra uma queda de 2,4\% projetada para 2016 (AGÊNCIA DE NOTICIAS DO PARANÁ).

A sojicultura foi introduzida no Paraguai no início da década de 1970 , dentro de um processo de expansão da sojicultura brasileira, quando produtores brasileiros adquiriram terras, especialmente nos Departamentos do Alto Paraná, Itapúa e Canindeyú, região leste do país (PEIXINHO, SOUZA E SCOPEL, 2009). A janela de plantio da soja no Paraguai se abre no início de setembro, pouco antes que no Brasil, e a colheita começa em janeiro. Sua grande produção coloca o país apenas atrás do Brasil, Argentina e Estados Unidos. A produção de soja tem grande importância para o pais, correspondendo a 40\% da sua receita (CAPECO, 2017). 
A união dos prêmios de produção do Paraguai, confirmou um recorde de produção, tanto em volume quanto em produtividade de soja no país, que alcançou $3.147 \mathrm{~kg}$ por hectare e 10.664.613 toneladas no total. A área plantada na safra 2016/2017 foi de aproximadamente 3.388.709 hectares, com picos e volumes de rendimento devido a um maior nível de investimentos, clima favorável e tecnologias aplicadas. As regiões com maior índice de produtividade no Paraguai foram os departamentos de Canindeyu, Alto Parana e Itapua, regiões essas que correspondem a $65 \%$ da produção nacional.

\section{PROCEDIMENTOS METODOLÓGICOS}

A presente pesquisa se caracteriza como qualitativa-comparativa. De acordo com Flick (2009), a pesquisa qualitativa visa abordar o mundo "lá fora", entender, descrever e explicar os fenômenos sociais "de dentro" de diversas formas. Por outra maneira, o estudo comparativo permite identificar fenômenos complexos, com a comparação da atuação de organizações que pertencem a setores diferentes ou comparação entre diversas organizações do mesmo setor (BULGACOV, 1998).

Além disso, foi realizada por meio de estudo multicaso, pois o estudo multicaso possibilita levantar evidências relevantes e de maior confiabilidade se comparado aos estudos de casos únicos (YIN, 2001). Utilizou-se do uso da aplicação de questionários com produtores em duas cooperativas, a primeira sendo a AGROPAR - Cooperativa Agropecuária do Médio Oeste do Estado do Paraná, unidade de Assis Chateaubriand, pertencente ao Estado do Paraná no Brasil e a segunda Cvale - Cooperativa Agroindustrial, também brasileira, mas como objeto de estudo dessa pesquisa, foram selecionados produtores da unidade da Cvale no município de Corpus Christi, Estado de Canindeyu no Paraguai.

Foram selecionados 10 produtores em cada cooperativa de forma não-probabilística, que apresentaram os melhores resultados de produtividade nas regiões avaliadas, durante a safra de soja 2016-2017, para a obtenção de dados sobre os produtores, analisando algumas técnicas de manejo da lavoura e questões relacionados ao perfil do produtor.

Ciências Sociais Aplicadas em Revista, v. 20, n. 38, p. 167-185, semestral, janeiro-junho, 2020. 


\section{RESULTADOS E DISCUSSÃO}

Dos produtores entrevistados, verificou-se média de idade de anos vividos de 46,70 anos para os produtores brasileiros, e de 39,70 anos para os produtores paraguaios. As menores idades dos produtores paraguaios ajudam a verificar a média de escolaridade dos produtores avaliados, como mostra na figura 1 , onde observa-se um grau de escolaridade mais elevado referente aos produtores paraguaios. Sobre os produtores do país vizinho, não necessariamente são de nacionalidade paraguaia, todos os produtores entrevistados são brasileiros, e foram ao pais vizinho em busca de novas oportunidades, são os chamados "brasiguaios".

Fato relacionado aos produtores Paraguaios, é que a sucessão familiar no controle dos negócios é realizada mais cedo que no Brasil, como percebemos pela média de idade dos produtores avaliados.

Figura 1 - Nível de escolaridade dos produtores

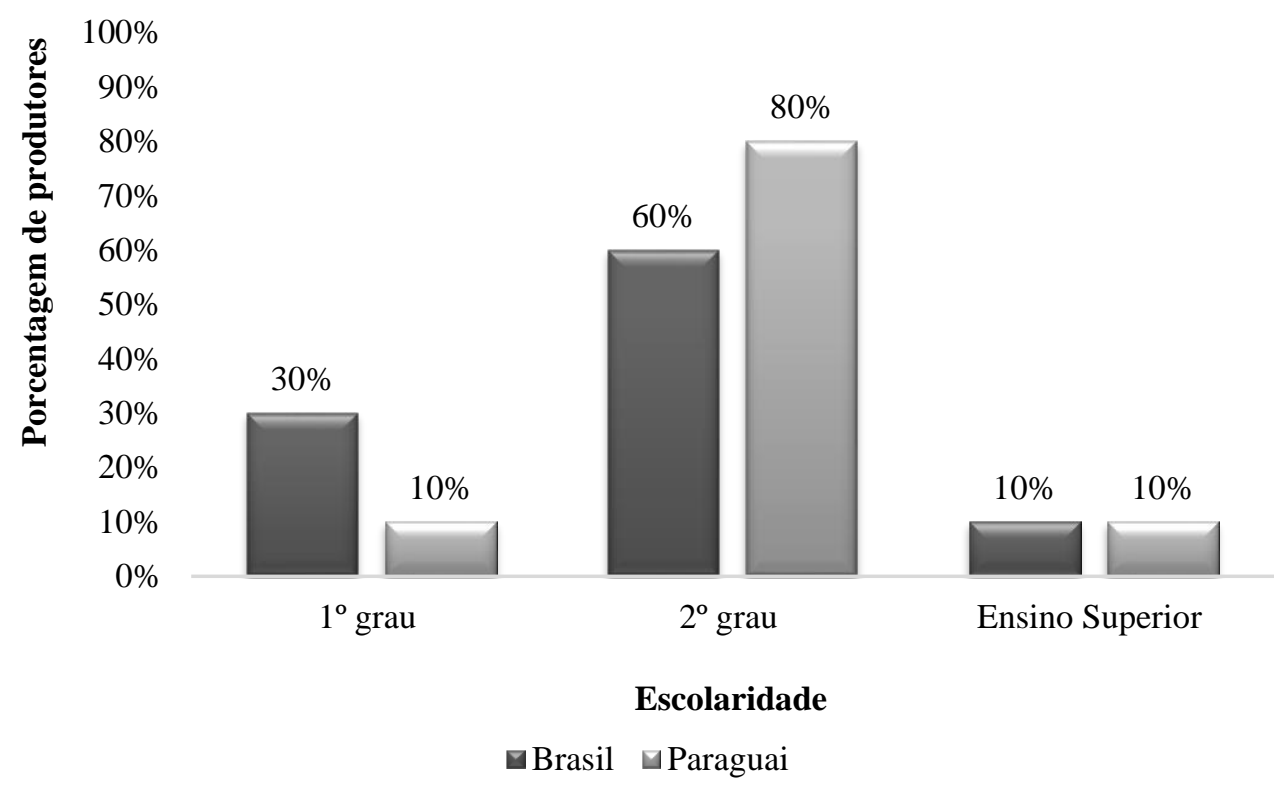

A figura 2 apresenta as médias de produtividade das cinco últimas safras dos produtores avaliados. Percebe-se que a região do Brasil esteve à frente do Paraguai nas médias de produtividade, nas últimas 5 safras, e na mais recente safra obteve a maior média de produtividade, com 75,87 sacas/ha, o que representa $13,62 \%$ a mais que a média obtida no Paraguai que foi de 65,53 sc/ha. A média das áreas avaliadas no Brasil foi de 115,12 ha, já no Paraguai a média foi de 639,72 ha. Essa diferença no tamanho na média das áreas avaliadas de mais de mais $179 \%$ em relação as áreas brasileiras podem ter colaborado na obtenção de menor média de produtividade na 
região Paraguaia. É fato que no Paraguai os produtores possuem áreas maiores em relação aos produtores do Brasil, nas regiões avaliadas.

Os dados obtidos na pesquisa mostram satisfação dos produtores brasileiros e paraguaios em relação as condições meteorológicas da última safra. Os produtores brasileiros consideraram como boas essas condições, já no Paraguai, 90\% dos entrevistados consideraram excelente, e 10\% dos produtores consideraram boas, as condições climáticas da última safra de soja.

Figura 2 - Produtividade média das 5 últimas safras de soja - sc/ha

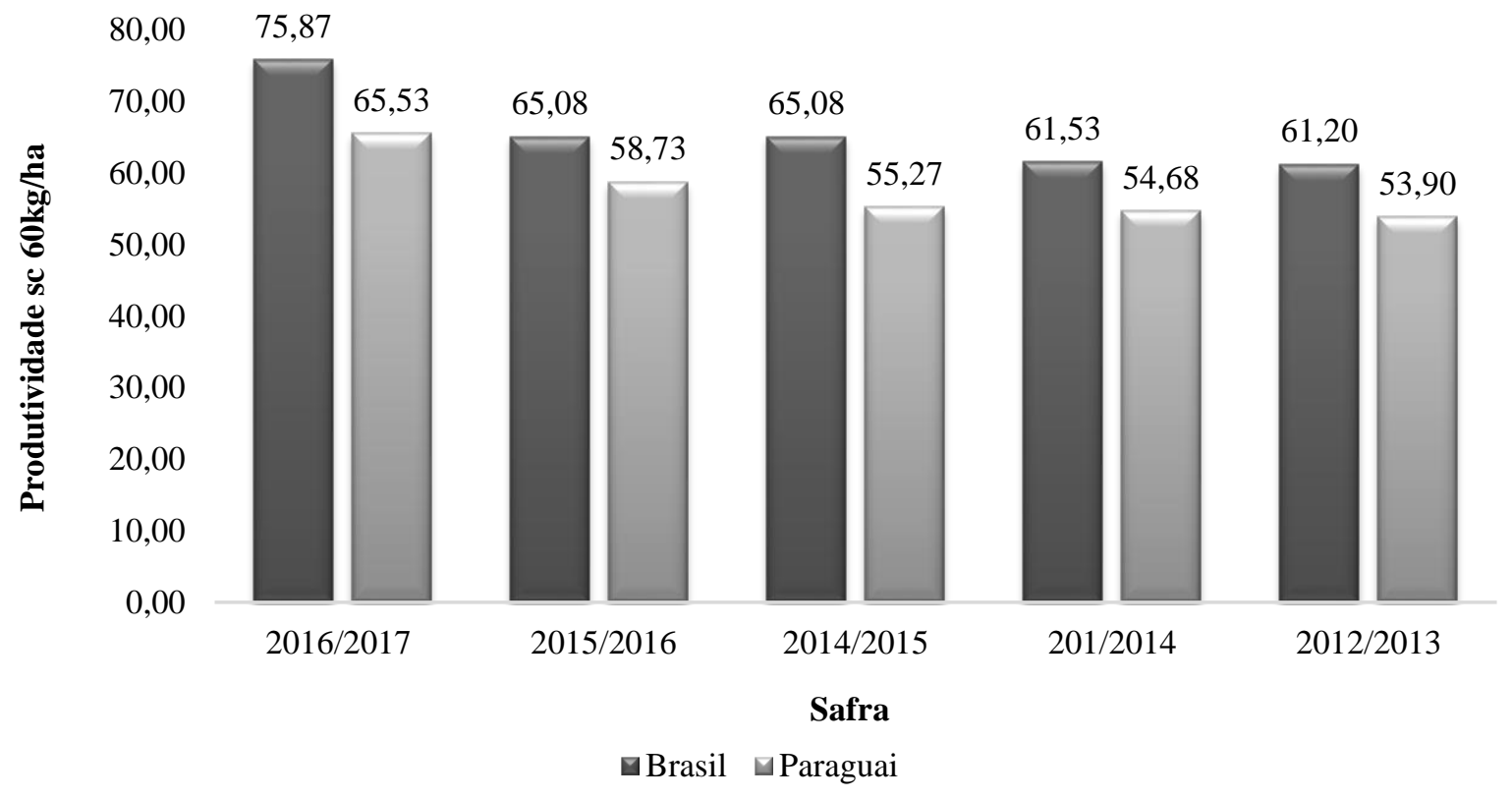

O Brasil também foi superior na pesquisa do material de soja cultivado que obteve a maior média de produtividade na área cultivada dos produtores avaliados, com média de 79,96 sc/ha, contra 67,58 sc/ha dos produtores dos Paraguai.

A figura 3 faz um comparativo das tecnologias de soja utilizada, entre soja resistente ao herbicida glifosato (soja RR) e soja resistente ao glifosato e resistente a lagartas (soja intacta). Na figura abaixo percebe-se maior adoção de soja intacta na região do Brasil. 
Figura 3 - Tecnologia de soja utilizada
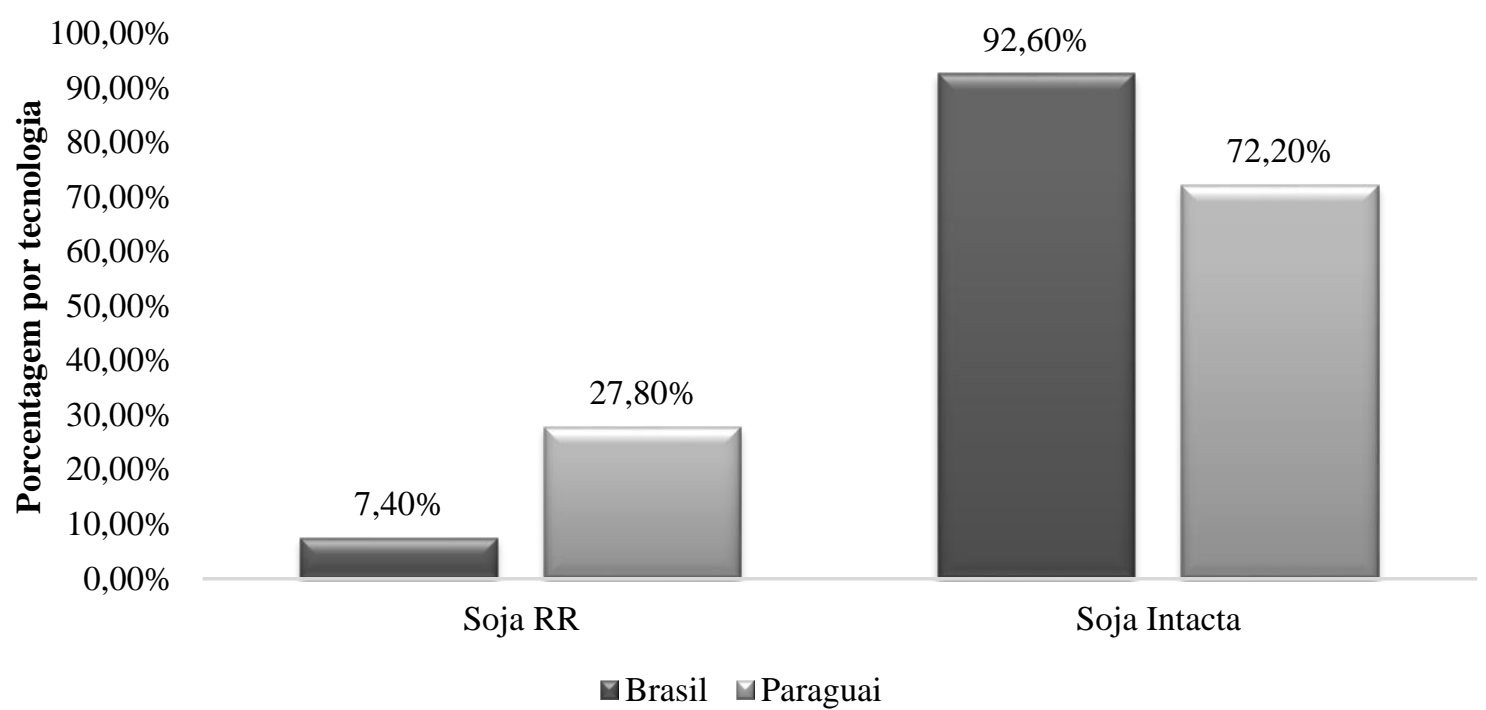

Com relação a área plantada com soja Intacta RR2 Pro da Monsanto, se confirmadas as vendas projetadas pela Monsanto, a soja Intacta estará presente entre $31 \%$ a $38 \%$ das lavouras desses quatro países na safra 2016/2017 (NOTÍCIAS AGRÍCOLAS).

Em relação ao uso de tecnologia, figura 4, onde foi avaliado produtores que utilizaram método a agricultura de precisão para realizar a correção dos níveis de fertilidade do solo, e também produtores que possuem máquinas equipadas com instrumentos de agricultura de precisão. Nas duas regiões avaliadas encontraram-se valores semelhantes, o que comprova alto uso de tecnologia nos dois países produtores. 
Figura 4 - Utilização de tecnologia (agricultura de precisão)

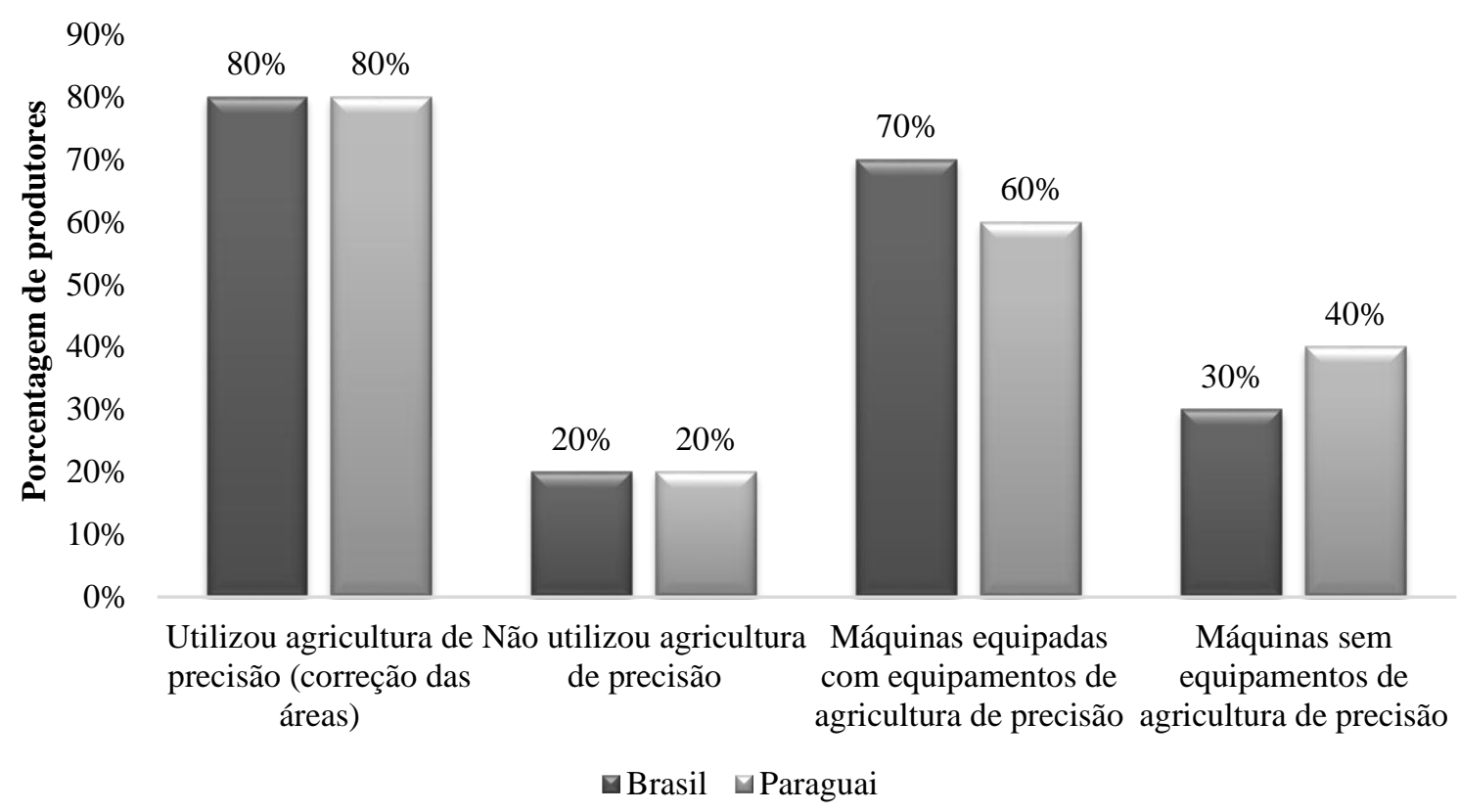

Em seu trabalho, Costa e Guilhoto (2011), relatam que os principais benefícios gerados pelo uso de agricultura de precisão são: redução nos custos pela diminuição no uso de insumos agrícolas, redução na poluição da agua e do ambiente e aumento da produtividade agrícola pela aplicação mais eficiente dos insumos.

Gasques et al. (2004), ao analisar a produtividade total dos fatores da agropecuária brasileira, consideram a tecnologia e as inovações como responsáveis pelos crescentes ganhos de produtividade do trabalho da agropecuária brasileira nas últimas décadas. $\mathrm{O}$ aumento de produtividade está relacionado em grande parte ao uso de maquinas e equipamentos.

O uso de maquinas modernas também contribui com a obtenção de maiores produtividades, como podemos conferir o fato em relação as máquinas que vem sendo utilizadas pelos produtores no processo de produção, pode-se verificar neste estudo um média de 2 anos das máquinas utilizadas tanto no Brasil, quanto no Paraguai.

A figura 5 avalia o uso de rotação de cultura e adubação com tecnologia. Pode-se analisar que quanto ao uso de adubação com tecnologia pelos produtores, ou seja, fertilizantes com melhor qualidade física e química, com todos os nutrientes presente num só grânulo, que permite uma melhor distribuição dos nutrientes no solo, liberação gradual dos nutrientes e melhor distribuição devido a homogeneidade dos grânulos. 
Figura 5 - Uso de rotação de cultura e adubação utilizada

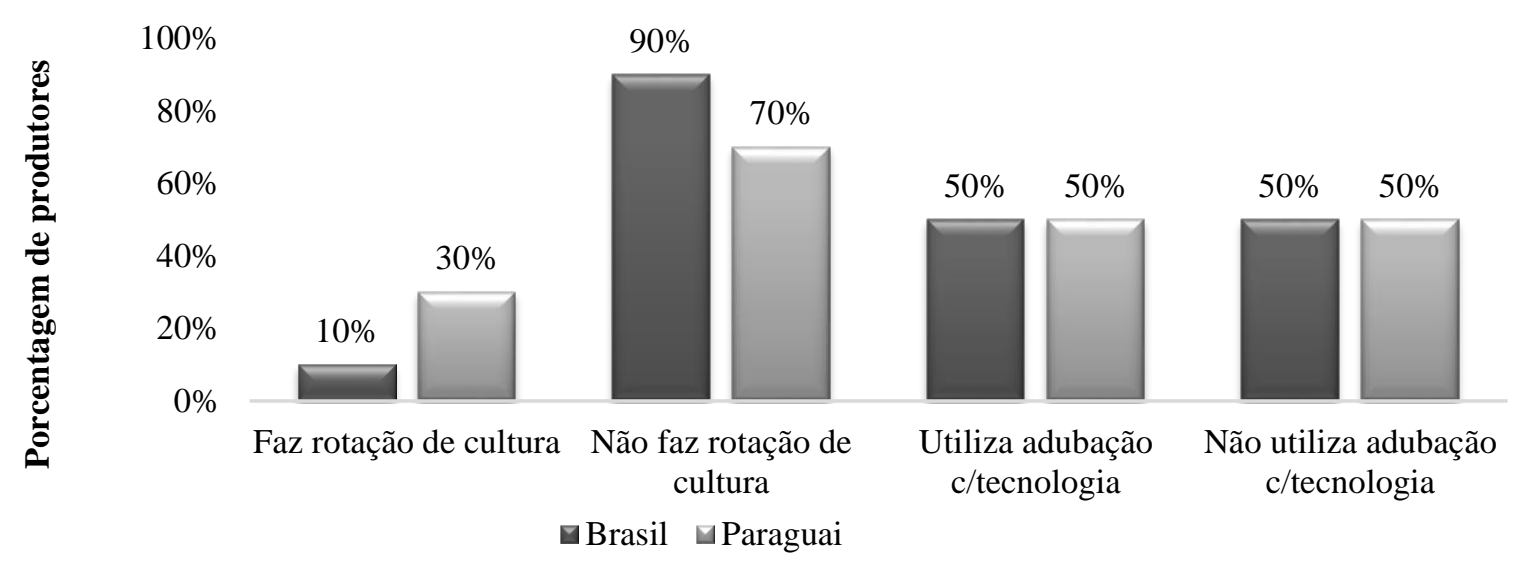

O uso de fertilizantes na agricultura inovou a produção de alimentos e proporcionou aumentos de produtividade muito significativos. Atualmente no mercado estão disponíveis diversos produtos, com diferentes nutrientes, formas químicas, granulometria e eficiência (VOGEL, 2014).

$\mathrm{Na}$ pesquisa pode-se notar que 50\% dos produtores nos dois países utilizam de uma adubação com maior tecnologia, os outros 50\% trabalham com uma adubação tradicional. O uso desses fertilizantes com maior tecnologia empregada é um ramo que está em expansão no mercado agrícola e que ainda tem muito para crescer, sendo um fator importante no aumento de produtividade.

Quanto a adoção de rotação de culturas (figura 5), percebe-se que nos dois países a adoção pelos agricultores foi baixa, sendo pouco superior a adoção entre os produtores Paraguaios, na quantia de $30 \%$. A maioria dos produtores avaliados trabalham com sucessão de culturas, com o cultivo de soja na safra de verão e o milho na safra de inverno. Dos produtores avaliados que fazem rotação de cultura, esses trabalham com a cultura do trigo, aveia, nabo forrageiro, braquiária e milheto na safra de inverno, para realizar a rotação de cultura. No Paraguai, $30 \%$ dos produtores trabalham realizando rotação de cultura, pois são produtores que tem áreas maiores e conseguem destinar parte de suas áreas para realizar esse processo.

A adoção da pratica de rotação de cultura, influencia positivamente nas qualidades físicas, químicas e biológicas do solo. Segundo Embrapa (2013), os principais benefícios da rotação de cultura são: aumento do teor de matéria orgânica do solo, menor incidência e severidades de pragas e doenças, redução da infestação de plantas daninhas, ciclagem de nutrientes e fixação biológica de Nitrogênio, produção de fitomassa da parte área e raízes que vão auxiliar no controle de erosão 
e também reduzir as perdas de agua por evaporação, redução da compactação do solo, ou seja, são benefícios para o sistema de produção como um todo.

Dos produtores paraguaios entrevistados, todos são de nacionalidade Brasileira, mas produzem no país vizinho. Esse vínculo que os produtores têm com o Brasil, pode ser um bom indicativo para comprovar os resultados até então discutidos, onde foram semelhantes quanto ao uso de tecnologia.

As questões abaixo relacionadas, fazem parte do estudo para avaliar o perfil do produtor em cada região analisada. Com os dados foi possível entender como o produtor trabalha, e analisar as diferenças entre os dois países.

A tabela 1 - analisa como é a forma que o produtor realiza a negociação dos insumos utilizados na produção. Os produtores brasileiros trabalham na maioria com compras para pagamento a vista. Com isso conseguem melhores preços nas negociações, comprando os insumos a menores preços, e obtendo assim menor custo de produção.

No Paraguai a grande diferença, é que os produtores negociam os insumos para pagamento no fim da safra, foi possível verificar que esses produtores preferem usar o produto e depois pagar, sendo um fato cultural do país.

Tabela 1 - Forma de negociação na compra de insumos

\begin{tabular}{ccccc}
\hline $\begin{array}{c}\text { Tipo de } \\
\text { negociação }\end{array}$ & Á vista & Prazo 30 dias & Prazo safra & Contrato \\
\hline Brasil & $60 \%$ & $10 \%$ & $30 \%$ & $0 \%$ \\
Paraguai & $0 \%$ & $0 \%$ & $100 \%$ & $0 \%$ \\
\hline
\end{tabular}

$\mathrm{Na}$ figura 6, analisou-se a importância que os produtores consideram no momento da compra dos insumos, analisando o preço em relação a eficiência dos produtos. Observa-se que os produtores Paraguaios se preocupam mais com o preço no momento da compra em relação aos produtores brasileiros, já esses se importam mais com a eficiência dos produtos, comparado aos produtores Paraguaios. $\mathrm{O}$ fato dos produtores paraguaios se importarem menos com a eficiência está ligado com o uso de produtos genéricos. 
Figura 6 - Importância do preço x eficiência do produto na escolha dos insumos

$80,00 \%$

$70,00 \%$

$60,00 \%$

$50,00 \%$

$40,00 \%$

$30,00 \%$

$20,00 \%$

$10,00 \%$

$0,00 \%$

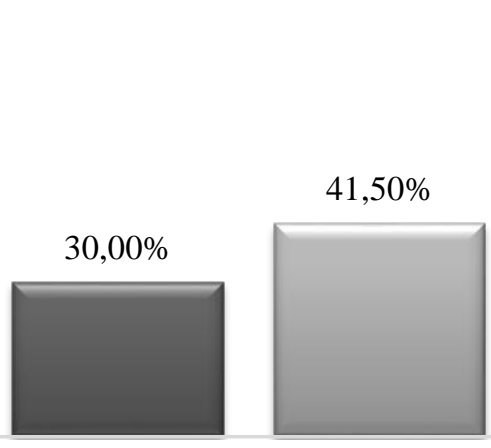

Preço

\section{$70,00 \%$}

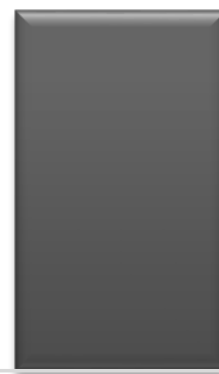

Eficiência
$58,50 \%$

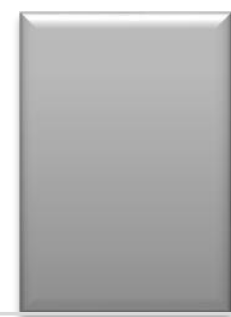

-

๑Brasil $\square$ Paraguai

A figura 7 mostra os fatores que influenciam na escolha dos insumos pelos produtores, dentre as palestras, os dias de campo, as pesquisas ou a internet. Os produtores brasileiros são influenciados pelas palestras e dias de campo, em ordem de importância, o que demonstra maior dependência dos canais de venda que geralmente trabalham.

Os produtores paraguaios relatam que são mais influenciados pela internet. Geralmente são produtores altamente profissionais e mais independentes dos canais de venda em relação aos produtores do Brasil. Esses produtores ficam boa parte do tempo conectados e atualizados a rede, com informações em tempo real. No Paraguai a internet é mais acessível, de melhor qualidade, inclusive em distantes localidades e com custos mais acessíveis, pode ser esses fatores que influencia a internet como a principal fonte de informações dos produtores no Paraguai.

Figura 7 - Fatores que influenciam na escolha dos insumos

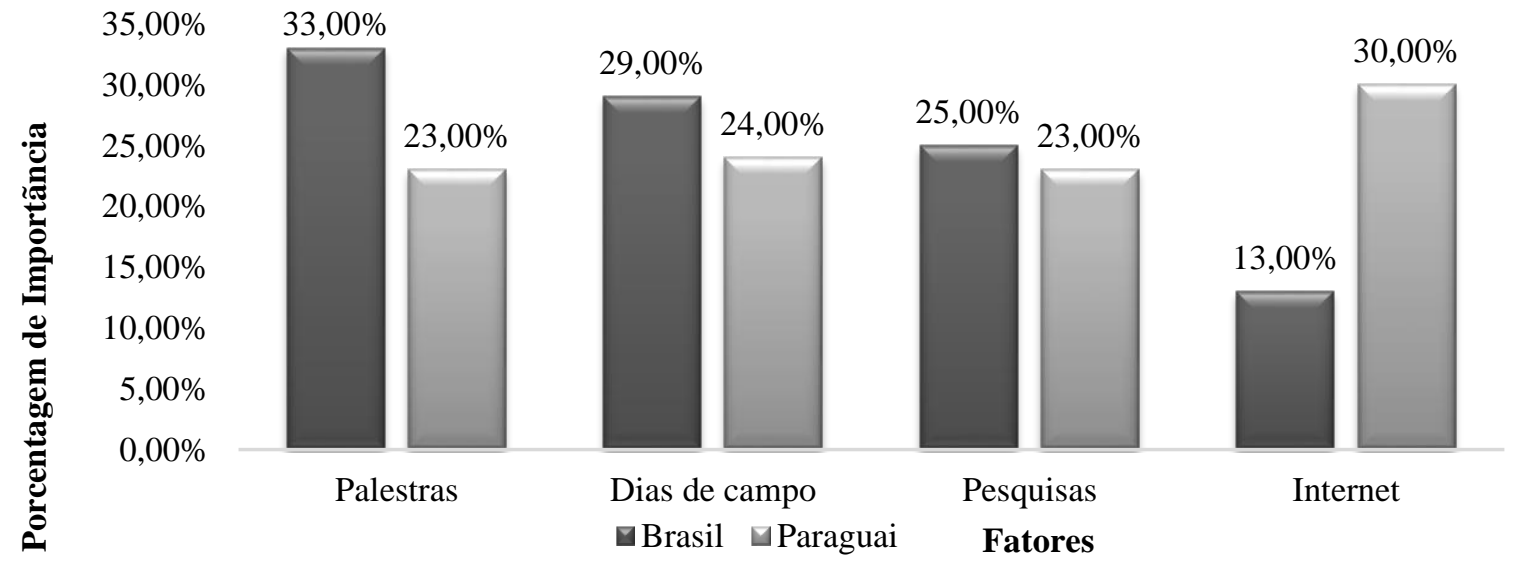

Ciências Sociais Aplicadas em Revista, v. 20, n. 38, p. 167-185, semestral, janeiro-junho, 2020. 
Na tabela 2 - mostra como produtores obtém informações sobre o preço das commodities, ou seja, como se mantem informados sobre mercado futuro, informações de safras, cotações do dia. Os resultados mostram que $60 \%$ dos produtores brasileiros se informam através da assistência técnica e $40 \%$ acompanham através da internet. A maioria está ligado a assistência técnica, o que comprova a maior dependência dos produtores brasileiros aos canais de venda, sendo revendas ou cooperativas.

Tabela 2 - Forma de obtenção de informações sobre preço das commodities

\begin{tabular}{ccccc}
\hline & Programa TV & Bolsa Chicago & Internet & Assistência técnica \\
\hline Brasil & $0 \%$ & $0 \%$ & $40 \%$ & $60 \%$ \\
Paraguai & $0 \%$ & $100 \%$ & $0 \%$ & $0 \%$ \\
\hline
\end{tabular}

No Paraguai a forma como que os produtores se mantem informados é totalmente através da Bolsa de Chicago. Oque reforça o fato que os produtores paraguaios serem mais informatizados, atentos as informações do meio agrícola e são menos dependentes dos canais de venda. Esses produtores obtêm informações importantes por conta própria, através dos meios de comunicação que utilizam.

Nos dois países, os produtores também diferem quanto a importância dos fatores na escolha do canal de venda (figura 8). No Brasil os fatores mais opinados foram em primeiro o preço e em segundo a assistência técnica. $\mathrm{O}$ fator do preço está ligado a conseguir comprar os insumos a um preço mais competitivo e obter menor custo de produção. A assistência técnica aparece como fator de segunda ordem de importância, devido aos produtores brasileiros serem mais dependentes da assistência e do canal de venda.

Já no Paraguai os fatores não se diferenciaram tanto. Em ordem de importância os fatores mais importantes foram: a confiança, a assistência técnica, o relacionamento e o preço. Esses fatores se dão devido ao histórico do cliente junto a empresa, um trabalho que é construído ao longo dos anos.

Ciências Sociais Aplicadas em Revista, v. 20, n. 38, p. 167-185, semestral, janeiro-junho, 2020. 
Figura 8 - Fatores importantes na escolha do canal de venda

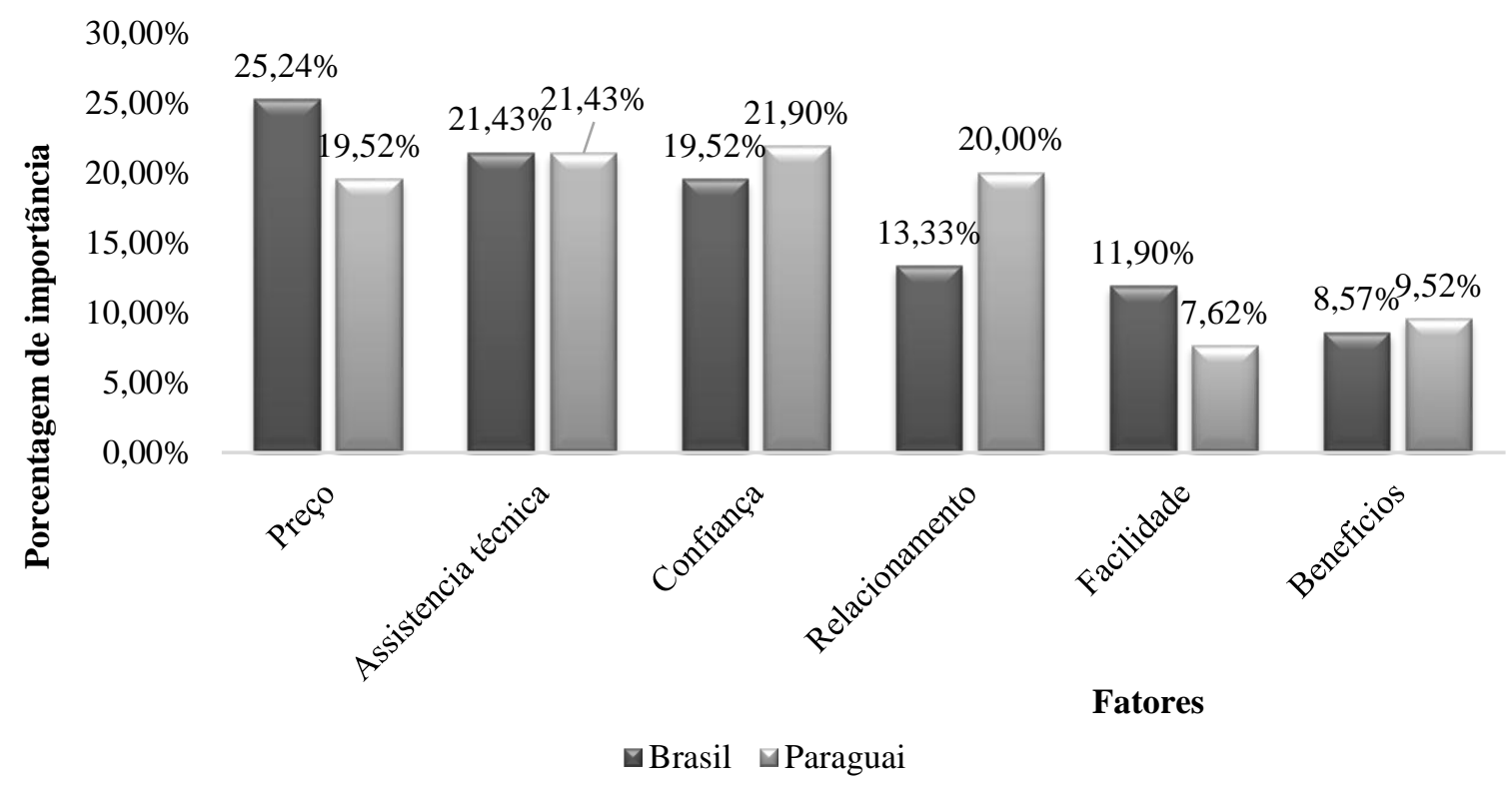

A tabela 3 - relata como é a forma que os produtores trabalham com a venda de sua produção. Os produtores brasileiros realizam a venda da produção em sua maior parte, 84,50\% através de venda balcão, onde é realizada a venda na cotação da commodities em que se encontra no dia e apenas $15,50 \%$ da produção é vendida antecipadamente através de contratos de entrega futura.

No Paraguai, os produtores trabalham mais com vendas antecipadas através de contratos de entrega futura no montante de $51 \%$. O fato desses produtores serem mais informados e atentos diretamente as cotações da bolsa de Chicago, faz com que eles trabalhem mais com contratos, onde assim travam seus custos de produção. Os produtores costumam trabalhar mais com contratos devido a segurança que eles têm com o preço fixado, evitando assim possíveis oscilações de preço do mercado.

Tabela 3 - Forma de venda da produção

\begin{tabular}{ccc}
\hline Forma de venda da produção & Contrato & Venda balcão \\
\hline Brasil & $15,50 \%$ & $84,50 \%$ \\
Paraguai & $51 \%$ & $49 \%$ \\
\hline
\end{tabular}

Na tabela 4 - avaliou-se o custo de produção, e a forma como o produtor controla seu custo. A forma como o produtor Paraguaio controla seu custo, demonstra um maior nível de informatização, onde no Paraguai $30 \%$ dos produtores tem uma forma informatizada de controle, 
já no Brasil o controle ainda é realizado de forma manual, através de anotações. Fato esse que ajuda a comprovar que no Paraguai os produtores estão mais informatizados em relação aos produtores brasileiros.

Tabela 4 - Custo de produção

\begin{tabular}{ccccc}
\hline & Custo de produção & \multicolumn{2}{c}{ Forma que realiza o controle } & \\
\cline { 2 - 4 } & $\begin{array}{c}\text { Possuem custo de produção } \\
\text { controlado }\end{array}$ & Manual & Informatizada & $\begin{array}{c}\text { Custo de } \\
\text { produção sc/ha }\end{array}$ \\
\hline Brasil & $90 \%$ & $100 \%$ & $0 \%$ & 25,89 \\
Paraguai & $100 \%$ & $70 \%$ & $30 \%$ & 24,30 \\
\hline
\end{tabular}

Foi avaliado também o custo de produção, obtendo valores próximos entre si. No Brasil o custo giro em torno de 25,89 sc/ha, contra 24,30 sc/ha no Paraguai em média.

\section{CONSIDERAÇÕES FINAIS}

A tendência da evolução tecnológica é se expandir mundialmente entre os países. Os produtores estão cada vez mais tecnificados e eficientes na produção de alimentos. A safra de soja 2016/2017, comprova esse uso de tecnologia com índices recordes de produtividade, e uma alta produção de soja até então nunca obtida nesses países.

Nos dois países avaliados, os produtores empregam alta tecnologia de produção e foram aumentando seus índices de produtividade no decorrer das safras. Nas regiões onde foi realizado o trabalho, avaliando a parte técnica, conclui-se que nos dois países os produtores possuem perfis semelhantes quanto ao uso de tecnologia. Esse fato pode ser explicado pelo motivo dos produtores Paraguaios entrevistados, serem de nacionalidade Brasileira, por isso tem um forte vínculo com o país.

Analisando o perfil do produtor, encontra-se diferenças nos dois países. No Brasil os produtores são mais dependentes da assistência técnica e dos canais de venda, onde buscam as informações e se mantem atualizados sobre o meio agrícola. No Paraguai os produtores são mais independentes das empresas que comercializam insumos e se mantem informados através dos meios de comunicação, dos quais estão constantemente conectados.

O presente estudo se justifica em função de analisar as principais características e formas de atuação de ambos os produtores. Pode-se verificar um perfil interessante por parte dos produtores no Paraguai, onde-se pode exemplo, a sucessão familiar tem ocorrido mais cedo e se

Ciências Sociais Aplicadas em Revista, v. 20, n. 38, p. 167-185, semestral, janeiro-junho, 2020. 
mostram profissionais quanto a busca de informações e atuação no mercado de commodities em bolsas de valores.

\section{REFERENCIAS}

Adapar mantém suspensão de produtos ineficientes no combate à ferrugem asiática. 2016. GAZETA DO POVO. Disponível em: <http://www.gazetadopovo.com.br/agronegocio/agricultura/adapar-mantem-suspensaode-produtos-ineficientes-no-combate-a-ferrugem-asiatica-29kv9xwyqkc3u3vkyy7asw114> Acesso em: 15 set. 2017.

AGÊNCIA DE NOTICIAS DO PARANÁ - AEN. Paraná é o primeiro no mundo na produtividade de soja. 2017.2 Disponível em $<$ http://www.aen.pr.gov.br/modules/noticias/article.php?storyid=93562\&tit=Parana-e-o-primeirodo-mundo-na-produtividade-de-soja> Acesso em: 22 ago. 2017.

BULGACOV, S. Estudo comparativo e de caso de organizações e estratégias. Organização e Sociedade, Salvador, Bahia, v. 5, n.11, 1998.

BOSCO, J. H. Série especial: força da agricultura coloca Paraguai entre os líderes no mercado da soja. Canal Rural. 2014. Disponível em: <http://www.canalrural.com.br/noticias/soja-brasil/serieespecial-forca-agricultura-coloca-paraguai-entre-lideres-mercado-soja-24636> Acesso em: 23 ago. 2017.

Cámara Paraguaya De Exportadores Y Comercializadores De Cereales Y Oleaginosas - CAPECO. 2017. Disponível em:<http://capeco.org.py/> Acesso em: 23 ago.2017.

CAMPO, R. J.; HUNGRIA, M. Como a soja pode produzir mais. Revista Cultivar, n.20, p.4849. 2000. Disponível em: <http://www.grupocultivar.com.br/artigos/como-a-soja-pode-produzirmais>. Acesso em: 25 mar. 2017.

Campeão em produtividade gasta R \$ 1.800 por hectare. Canal Rural. 2015. Disponível em: $<$ http://www.projetosojabrasil.com.br/campeao-produtividade-colhe-140-sacas-gastandopouco/.>. Acesso em: 25 mar. 2017.

Companhia Nacional de Abastecimento - CONAB. Acompanhamento da safra Brasileira de Grãos 2016/2017, sexto levantamento. v.4, n.3, Brasília: Conab, 2017. Disponível em <http://www.conab.gov.br/OlalaCMS/uploads/arquivos/17_03_14_15_28_33_boletim_graos_ma rco_2017bx.pdf> Acesso em: 25 mar. 2017.

Companhia Nacional de Abastecimento - CONAB. Acompanhamento da safra Brasileira de Grãos Safra 2016/2017, décimo levantamento. v.4, n.10, Brasília: Conab, 2017. Disponível em: <http://www.conab.gov.br/OlalaCMS/uploads/arquivos/17_07_12_11_17_01_boletim_graos_ julho_2017.pdf> Acesso em: 22 ago. 2017.

COSTA, C. C.; GUILHOTO, J. J. M. . Impactos da agricultura de precisão na economia brasileira. In: Inamasu, R. Y.; Naime, J. de M.; Resende, A. V. de; Bassoi, L. H.; Bernardi, A. C. de C. (Org.). 
Agricultura de precisão: um novo olhar. 1ed.São Carlos: Embrapa Instrumentação, 2011, v. , p. 307-322.

Empresa Brasileira de Pesquisa Agropecuária - EMBRAPA. Nutrição equilibrada da soja para altas produtividades - Uma abordagem filosófica. 2013. Disponível em< https://ainfo.cnptia.embrapa.br/digital/bitstream/item/92321/1/Nutricao-equilibrada-da-soja-paraaltas-produtividades-uma-abordagem-filosofica.pdf> Acesso em: 25 mar. 2017.

Empresa Brasileira de Pesquisa Agropecuária - EMBRAPA. Embrapa Soja. Disponível em <https://www.embrapa.br/soja/cultivos/soja1> Acesso em: 25 mar. 2017.

FELEMA, J.; RAIHER, A. P.; FERREIRA, C. R. Agropecuária brasileira: desempenho regional e determinantes de produtividade. Revista de Economia e Sociologia Rural (Impresso), v. 51, p. 555-573, 2013.

FLICK, Uwe. Desenho da Pesquisa Qualitativa. 1. ed. Porto Alegre: Artmed, 2009.

GLAUSER, M. Extranjerización del territorio paraguayo. Asunción: BASE IS, 2009.

GONÇALVES, S.P.; NEVES, E. M.; GONÇALVES, J.S. Feijão: produtividade e consumo. Agroanalysis (FGV), v. 27, p. 13-14, 2007.

GRAY, E.; JACKSON, T.; ZHAO, S. Agricultural productivity: concepts, measurement and factors driving it - a perspective from the ABARES productivity analyses. Rural Industries Research and Development Corporation, Australian Government, n. 10, p. 56, mar. 2011.

Instituto Paranaense de Desenvolvimento Econômico e Social - IPARDES. Paraná lidera produtividade de soja e milho no País, diz IBGE. 2016. Disponível em: $<$ http://www.ipardes.gov.br/index.php?pg_conteudo=1\&cod_noticia=754>. Acesso em: 25 mar. 2017.

MOREIRA, D. A. Medidas da produtividade na empresa moderna. São Paulo: Pioneira, 1991.

Monsanto vê alta de até $57 \%$ na área de soja Intacta na América do Sul em 16/17. Notícias Agrícolas. Disponível em: <https://www.noticiasagricolas.com.br/noticias/soja/179318monsanto-ve-alta-de-ate-57-na-area-de-soja-intacta-na-america-do-sul-em1617.html\#.WbvPAsiGPIU>. Acesso em: 15 set. 2017.

PEIXINHO, D. M.; SOUSA, M. S.; SCOPEL, I. A organização da produção mundial de soja e sua espacialização nos países Sul-Americanos. In: $12^{\circ}$ Encuentro de Geógrafos de América Latina, 2009, Montevideo. Caminhando en una América Latina en transformación, 2009.

ROJAS, L. Actores del Agronegocio en Paraguay. Assunção: BASE IS, 2009.

VIEIRA FILHO, J. E. R.; SILVEIRA, J. M. F. J. da. Modelo de aprendizado agrícola. Revista Brasileira de Inovação, v. 10, p. 265-300, 2011.

VIEIRA FILHO, J. E. R.; SILVEIRA, J. M. F. J. da. Mudança tecnológica na agricultura: uma revisão crítica da literatura e o papel das economias de aprendizado. Revista de Economia e Sociologia Rural (Impresso), v. 50, p. 721-742, 2012. 
VOGEL, P. T. Estratégias de aplicação e fontes de fertilizantes na cultura da soja. Dissertação de Mestrado - Universidade Federal de Santa Maria, Colégio Politécnico, Programa de PósGraduação em Agricultura de Precisão, RS, 2014.

YIN, R.K. Estudo de caso: planejamento e método. Tradução de Daniel Grassi. 2.ed. Porto Alegre: Bookman, 2001. 